\title{
Cíntia Moscovich e Carol Bensimon: a personagem homossexual feminina na literatura brasileira contemporânea Juliana Gervason Defilippo ${ }^{1}$
}

Este artigo busca refletir sobre duas obras da produção brasileira contemporânea, com o intuito de identificar os valores ligados à cultura e suas especificidades na construção identitária feminina, procurando estabelecer não apenas uma breve análise das obras mas também uma reflexão a respeito do lugar da personagem homossexual feminina na narrativa atual. Os livros escolhidos para essa análise comparativa são Duas iguais, de Cíntia Moscovich, publicado em 2004, e Todos nós adorávamos caubóis, de Carol Bensimon, publicado em 2013.

As escritoras em análise dialogam e compartilham o mesmo espaço de um significativo rol de escritores que, de acordo com a pesquisadora Beatriz Resende (2008), refletem a fertilidade, a qualidade e a multiplicidade que marcam a produção literária atual. Essas três características comungam para que obras de periferia ou produzidas por grupos excluídos possam fazer parte de uma parcela legítima - e hoje, significativa - da produção editorial.

Diferentemente de escritoras tais como Cassandra Rios ou Adelaide Carraro, que ocuparam nos anos 1970 um espaço popular, porém ínfimo das publicações em torno do tema, ou de escritoras pós-1990, que só encontraram acesso no escasso catálogo das editoras e seus tímidos selos GLS, Cíntia Moscovich e Carol Bensimon pertencem ao corpo de autores da Record e Companhia das Letras, respectivamente. Considerando os estudos da pesquisadora Regina Dalcastagnè (2012) e sua constatação de que estas empresas figurariam como grandes editoras ativas no Brasil, ressalta-se a relevância de terem as duas publicações alcançado um espaço até então restrito, tanto para mulheres quanto para a temática aqui analisada.

Cabe, no entanto, outra reflexão: a multiplicidade positivamente levantada por Beatriz Resende (2008) compartilha um espaço ainda tumultuado em relação ao pesquisado por Regina Dalcastagnè (2012). Ou seja, há atualmente uma literatura que é, ainda, produzida em sua

\footnotetext{
${ }^{1}$ Doutora em estudos literários e professora do Programa de Mestrado em Letras do Centro de Ensino Superior de Juiz de Fora (CESJF), Juiz de Fora, MG, Brasil. E-mail: julianagervason@ pucminas.cesjf.br
} 
maioria por escritores do sexo masculino, brancos e heterossexuais. Segundo o pesquisador inglês Faramerz Dabhoiwala, em sua obra As origens do sexo: uma história da primeira revolução sexual (2013), "os ideais de liberdade sexual viriam a se tornar muito mais amplamente aceitos a curto prazo, o seu avanço, como outros tipos de liberdade, beneficiou, acima de tudo, uma minoria de homens brancos heterossexuais e detentores de propriedade" (Dabhoiawala, 2013, p. 19).

É possível que isso explique, ou ao menos justifique, o fato de o retrato da personagem homossexual feminina na literatura sobretudo nas mãos de um escritor do sexo masculino - declinar para uma excessiva sexualização da mulher, com enredos em que as descrições das cenas de sexo e seu detalhamento sejam o que prevalece na produção ficcional (como será possível perceber mais adiante, no breve levantamento de autores apresentado). Dabhoiwala (2013) afirma que "as vozes de mulheres reais em primeira mão são muito mais difíceis de recuperar. Mesmo dentro do casamento, é raro encontrar, antes do século XVIII, textos de correspondência feminina que façam sequer vaga alusão à paixão sexual" (Dabhoiwala, 2013, p. 39). Dessa forma, problematizamos ainda: haveria espaço para uma literatura sobre a personagem feminina homossexual? Mesmo que essa não seja a discussão desenvolvida neste artigo, cabe uma tímida resposta: não.

Um breve levantamento da produção dos últimos 25 anos no catálogo de grandes editoras (entre elas Companhia das Letras e Record) demonstra que há ainda poucas personagens femininas e infinitamente menos personagens homossexuais femininas. Cabe destacar que, nesse rol de obras, não se exclui aquela feita por escritores do sexo masculino. Afinal, cabe tanto ao homem quanto à mulher produzir literatura. Mas, mesmo entre os que prevalecem nos catálogos das editoras mais conhecidas e com um número maior de autores, o interesse continua voltado para a heterossexualidade ou a homossexualidade masculina, hoje muito em voga. A esse respeito, o pesquisador Luiz Mott, já na década de 1980, afirmava:

se para os gays masculinos houve um verdadeiro complô de silêncio dos donos do poder e de seus escribas, destruindo-se evidências comprobatórias do amor unissexual entre membros do sexo forte, no caso do lesbianismo a falta de documentos se deve mais à cegueira, indiferença e preconceito dos homens face à 
sexualidade feminina, considerada assunto de menor importância e indigno de atenção do sexo forte (Mott, 1987, p. 8).

Logo, conforme constata Beatriz Resende (2008), dentro da diversidade que apresenta a literatura contemporânea, há realmente questões predominantes e preocupações que se manifestam com frequência, mas a questão aqui analisada neste artigo não é, por enquanto, uma delas.

A delimitação do corpus deste artigo, privilegiando a produção de duas mulheres, não se apresenta como uma tentativa de restringir a análise da personagem homossexual feminina, apenas quando apresentada por mulheres. A apropriação das obras e sua relação fez-se em função da temática em questão: o amor - embora pese o fato de que esse tipo de personagem homossexual feminina, dentro dessa abordagem temática, apareça com timidez na literatura escrita por homens.

Cíntia Moscovich e Carol Bensimon usufruem de uma certa vantagem ao lado das mulheres de suas gerações: escrever depois do movimento feminista - tal como atesta Beatriz Resende (2008) ao falar da produção de outras escritoras. Porém é preciso destacar que, assim como as escritoras dos anos 1960 e 1970 buscaram via literatura uma forte necessidade de afirmação de gênero, as autoras aqui contempladas fazem parte de uma geração que precisa, primeiro, demarcar um território já mais bem percorrido pelos homens. Em outras palavras, é possível perceber uma forte tentativa da banalização do discurso via personagens femininas. Esse esforço tem o intuito de torná-lo comum, retirando da construção narrativa e dos rótulos que os livros recebem o status de exótico, transgressor ou restrito a um público muito específico. Sendo assim, é possível notar - nas duas narrativas - que as autoras percorrem um caminho já traçado e percorrido por outros autores, ${ }^{2}$ quando da abordagem de personagens homossexuais masculinos, mas ainda pouco explorado no campo feminino.

Enquanto Cassandra Rios e outras escritoras de sua geração despertavam/buscavam criar certo desconforto ao apresentar suas personagens em obras de latente erotismo e vulgaridade, como em Eu sou uma lésbica (1983), as personagens das duas obras aqui analisadas apresentam-se tão comuns quanto qualquer outra personagem ali

\footnotetext{
${ }^{2}$ A título de exemplo, cabe citar os contos e romances de Caio Fernando Abreu, atualmente explorados em pesquisas cujo foco é a homoafetividade no campo literário.
} 
delineada - tanto feminina, quanto masculina. A sexualidade é uma de suas características, não a única ou a predominante, assim como são características também a cor do cabelo, a cor dos olhos ou a nacionalidade. Há, é evidente, a perspectiva feminina tanto na concepção autoral dos livros, quanto na construção narrativa, assim como não há as mediações tradicionais que sustentaram o discurso literário brasileiro (masculino e heterossexual). Citando novamente Beatriz Resende (2008), trata-se de uma "afirmação anticânone, responsável por renovação artística, garantia de inovação e possibilidade de olhares dos quais o cânone masculino não foi capaz" (Resende, 2008, p. 109). ${ }^{3}$

Devassos no paraíso, de João Silvério Trevisan, publicado em 1986 (revisado e ampliado nos últimos anos), apresenta um relevante mapeamento da produção literária brasileira dentro da perspectiva homossexual. O estudo serve como mais um ratificador do duplo silenciamento feminino: não há espaço para a presença lésbica na literatura brasileira, porque essa presença não se fez evidente. É Luiz Mott, em 1987, quem tenta preencher essa lacuna, ao publicar O lesbianismo no Brasil e trazer um levantamento da história da mulher homossexual na literatura, citando desde Gregório de Matos a Cassandra Rios. O estudo de Mott corrobora com o que aqui se busca problematizar: há uma excessiva caricaturização da figura feminina quando esta é transportada para o campo narrativo. Do duplo silêncio ao qual foi relegada por uma sociedade patriarcalista e heterossexual, a mulher transita para uma fala ainda desviada da realidade e, assim como na história da homossexualidade masculina, com um atraso de dezenas de anos. A figura feminina passa a ser descrita como exótica, caricatural e restrita aos rótulos relegados aos silenciados pela exclusão. Quem era a homossexual feminina pouco importava, desde que a mesma fosse transformada em algo tão peculiar quanto um representante de outro planeta na ficção científica, por exemplo.

Segundo Mott, o poeta barroco Gregório de Matos Guerra representaria a primeira manifestação literária brasileira em que há referência à homossexualidade feminina. Em alguns de seus sonetos, é possível

\footnotetext{
${ }^{3}$ Ao afirmar o relativo ineditismo do tema, não estamos ignorando a androginia feminina, já explorada em escritoras como Clarice Lispector ou Lygia Fagundes Telles, por exemplo. A sexualidade das personagens criadas por essas autoras e outras suas contemporâneas não nos remetem à sexualidade que buscamos explorar através de Cíntia Moscovich ou Carol Bensimon.
} 
perceber a vulgarização da figura feminina, referenciada com termos pejorativos da época - alguns eternizados até os dias atuais - assim como relegada a devassidão e heresia: "Maribonda, minha ingrata, tão pesada ali se viu,/que desmaiada caiu, sobre Luiza Sapata:/viu-se uma e outra mulata em forma de sodomia" (Matos apud Mott, 1987, p. 69).

Da vulgarização no Barroco, Mott apresenta no Romantismo a visão anuladora da figura feminina, uma vez que Joaquim Manoel de Macedo cria certa confusão ao narrativizar esse tipo de personagem, tornando-a "não mulher". Tanto no início de seu livro As mulheres de Mantilha (1870), quando descreve a mulher como guerreira com traços predominantemente masculinos, quanto no final do livro, ao transformá-la literalmente em homem, uma vez que era um representante deste sexo travestido de mulher:

Em As mulheres de Mantilha, Macedo reconstrói com precisão de etno-historiador e argúcia de psicólogo o universo doméstico de uma família burguesa, sendo uma das duas filhas do casal, Inês, 16 anos, quem desenvolverá bizarra paixão por Izidora, uma agregada de sua família. Na verdade, é só no final do romance que se esclarece que toda a paixão lésbica de Inês não passara de um fantasioso equívoco a que os juristas qualificariam como "erro de identidade" (Mott, 1987, p. 71).

A transgressão ao apresentar uma personagem homossexual feminina é remediada dentro da própria história por meio de um engano que a narrativa permite ao leitor cometer, mas que será corrigido por intermédio de um desfecho quase moralizante. Isso coloca as coisas em seu devido lugar e não desloca os valores tradicionais ainda que os tenha testado durante toda a narrativa.

Da vulgarização de Gregório à anulação de Macedo, Mott apresenta a animalização presente nas obras de Aluísio Azevedo, onde há não apenas a negação do eu feminino mas também seu deslocamento do humano. Em A condessa Vésper (1882), a personagem homossexual feminina diz: "meu corpo tem hoje de mulher a forma primitiva, habitao porém agora a alma de um demônio unissexual a quem desgostam as triviais carícias masculinas" (Azevedo apud Mott, 1987, p. 74). Já n'O cortiço (1890), a relação sexual entre as personagens é assim descrita: "agora, espolinhava-se toda, cerrando os dentes, fremindo-lhe a carne em crispações de espasmo; ao passo que a outra, por cima, doida de luxúria, irracional, feroz, revoluteava, em corcovos de égua, bufando e 
relinchando" (Azevedo apud Mott, 1987, p. 76). Para além da animalização própria do Naturalismo, há, nas referências feitas pelo autor, o veredito de que, segundo Mott, o "amor entre mulheres é torpe" (Mott, 1987, p. 77).

Mott apresenta um importante panorama da literatura brasileira em seu estudo, demonstrando passagens literárias que sustentam ser o amor entre mulheres abordado segundo perspectivas depreciativas. Seja vulgarizada, anulada ou animalizada, como nos autores citados, ou, ainda, estereotipada como a figura da mulher macho, representada no livro Luzia Homem (1903), de Domingos Olímpio, em que a personagem feminina é caracterizada como invertida na concepção plena do termo. Na década de 1920, o escritor Theo Filho (o menos conhecido dos citados no levantamento) publica o livro Dona Dolorosa (1922), que, segundo Mott, escandalizou a sociedade brasileira ao apresentar a homossexualidade feminina como uma anomalia, aberração, inversão, degeneração.

O estudo de Luiz Mott, aqui brevemente apresentado, demonstra que, de Gregório de Matos Guerra, no Barroco, a Theo Filho, já no Modernismo, não restou à personagem homossexual feminina nem um pouco de dignidade ou consolo: se eram destroçadas, anuladas e repelidas socialmente, que o fossem também no campo literário.

A trégua se faz pós-Semana de Arte Moderna, na mão de autores ainda menos cultuados que Theo Filho: Benjamin Constallat (com Mademoiselle Cinema), Charles Virmaitre (com Mademoiselle Saturno) e Laura Villares (com Vertigem). As obras levantadas por Mott resumem a nova fase de representação: não escapa à narrativa desses autores o ar blasé de suas homossexuais, contornadas por um espaço genuinamente francês - quando não original - e prontas para alimentar e satisfazer qualquer leitor em busca de certo voyeurismo.

Atualizando os estudos de Mott e buscando essa representação na produção mais recente e, sobretudo, na geração de Cíntia Moscovich e Carol Bensimon, é possível perceber uma desconstrução dessas imagens, gerando outras ainda passíveis de discussão e reflexão.

Duas iguais, de Cíntia Moscovich, foi publicado em 2004, praticamente isolada no cenário temático brasileiro. A narrativa, em primeira pessoa, conta a história de Clara e Ana, duas adolescentes que descobrem os prazeres do sexo e os encantos do amor em plena ditadura militar. $\mathrm{O}$ silêncio e o medo que rondam esse momento social e 
cultural intensificam-se na vida das meninas que, ao descobrirem suas predileções sexuais, precisam enfrentar o inquisidor olhar do pai de Clara e o destruidor olhar dos colegas da escola.

A obra, narrada por Clara, passa dos momentos da adolescência ao distanciamento das personagens na vida adulta, culminando no casamento heterossexual da narradora. O reencontro, já maduras, restabelece o amor adormecido entre ambas. Clara, a despeito de ser casada e possivelmente feliz com um homem, percebe que calar o amor que sentia - e ainda sente por Ana, possivelmente tenha sido sua pior decisão. A doença de Ana as aproxima através de uma angustiada experiência de arrependimentos, faltas e ausências. Não há como recuperar o tempo perdido, e a iminência da morte de Ana atesta para Clara que "o amor deve ecoar em bocas de prece, deve ser a nota mais alta, aquela que estilhaça o cristal e que entorna todos os líquidos" (Moscovich, 2004, p. 252).

Além dos dados relativos ao enredo, cabe ainda uma abordagem mais detalhada a respeito da descrição das personagens, foco da análise. Diferentemente da anulação, animalização, negação, inversão ou até mesmo vulgarização relegada às personagens homossexuais pelos antecessores literários aqui brevemente citados -, Moscovich as descreve como iguais, tanto no título do livro quanto na voz da personagem narradora Clara: "Existiu, me pergunto, algum momento em que fomos perfeitamente iguais?" (Moscovich, 2004, p. 16). A pergunta é feita nas primeiras páginas do livro e vai sendo respondida ao longo da história: "Me olhou, apoiada nas palmas das mãos, e pediu que eu me desse conta de que, naquela hora, éramos duas mulheres se amando e que nunca duas pessoas poderiam ser tão iguais" (Moscovich, 2004, p. 40). E ainda: "Até que um dia no pátio da escola, escutamos em alto e bom som: Qual de vocês é o homem? [...] aproximei-me da menina: como assim, o que ela queria dizer com aquilo? Nenhuma de nós era homem, nenhuma de nós. Ela estava escutando direito? Nenhuma de nós" (Moscovich, 2004, p. 45).

A consciência da exclusão e opressão social perpassa o livro a todo momento, mostrando que o movimento de afirmação e repúdio, através de uma literatura engajada, ainda que indiretamente, mantémse constante e necessário: "Era necessário que as duas fôssemos heroínas em tempo integral para nos salvar do massacre" (Moscovich, 2004, p. 46). Ou ainda: "Duas meninas lésbicas, era sempre o que concluíamos quando tentávamos descobrir o que nos acontecia; era 
isso a que estávamos reduzidas e nós não cabíamos em tão maldita redução" (Moscovich, 2004, p. 41). E mais: "Por quê, pai? Por que éramos a exceção? Por que eu era duplamente a exceção? Não era isso a desgraça, meu pai? Lésbica. Me olhava no espelho e não enxergava a lésbica ali. Eu queria Aninha, eu não queria nenhuma outra mulher, me desesperava" (Moscovich, 2004, p. 47).

As passagens atestam o quanto a obra valida um discurso contrário ao alimentado por outros escritores (femininos ou masculinos) de outros tempos, outras gerações. Não há aqui um retrato devasso das personagens, não há a anulação de suas identidades, e as cenas de sexo não tangenciam a obra e tampouco contribuem para suprir o voyeur olhar dos curiosos. Clara e Ana não são apenas duas mulheres iguais que se apaixonam e renegam qualquer tipo de rótulo ou redução, são também duas personas iguais e identificáveis por qualquer leitor da obra, seja ele homem, mulher, homossexual, heterossexual, bissexual, transexual etc. A identificação é plural porque é plural a caracterização das duas, assim como a temática que ora prevalece: "Eu queria contar uma história de amor" (Moscovich, 2004, p. 10); “Naquele momento, me dei conta de que o amor não pode viver escondido, que o amor demanda reverência coletiva" (2004, p. 48). Clara e Ana clareiam o que a literatura tentou manter no obscuro silêncio dos outsiders quando os estabelecidos lhe davam voz. O livro Duas iguais não conta uma história de duas personagens invertidas diferentes, lésbicas, sapatas, machonas - conforme os nomes redutores e negativos que a literatura as identificou durante anos -, mas apresenta ao público leitor apenas mais uma história de amor. Diferentemente da forma como as histórias de amor entre mulheres foram apresentadas pelos autores aqui referenciados, no levantamento de Mott, as mulheres na obra apresentam-se como duas pessoas que se amam, sem nenhum tipo de vulgarização, anulação, animalização ou exotismo diante do retrato apresentado das figuras femininas.

Quanto a Todos nós adorávamos caubóis, de Carol Bensimon, temos a história de Julia e Cora, duas jovens que se reencontram e decidem fazer a viagem que planejavam quando adolescentes, sobretudo, porque Cora decide levar a ideia adiante, num impulso dos que sabem que o minuto seguinte será de desistência. E Julia aceita, com a insegurança dos que ainda não estão certos a respeito do que querem seja viagem ou vida. Entre lembranças do passado e descrições dos 
caminhos que percorrem juntas, acompanhamos o desrelacionamento das duas: às vezes muito próximas, às vezes distantes e incomunicáveis. O livro não tem começo e não tem fim, a história apresenta-se como um flash de alguns meses na vida de duas mulheres que precisam se desconhecer para reconhecer quem são - no singular e no plural. Enquanto no movimento de Clara e Ana - no livro de Cíntia Moscovich - há o reconhecimento mútuo e devastador, no movimento de Julia e Cora há a solidão contemplativa dos que só conseguem se reconhecer porque há o outro: "Era realmente devastador chegar atrasada na minha própria vida pessoal" (Bensimon, 2013, p. 52).

Nos dois livros, o amor pleno e que desordena a vida das quatro personagens não se realiza. No livro de Cíntia Moscovich, é a morte que causa a separação; no de Carol Bensimon, é a vida:

Quando eu me lembrava de que era de certa maneira por minha causa que nós duas estávamos ali, por algum tipo de dívida moral do tempo da faculdade, uma prova tardia de que não havia nada a ser escondido, nem de um lado (eu) nem de outro (família), fosse o que fosse, quando eu me lembrava de que tínhamos subido mais de quatrocentos quilômetros para ver um túmulo, uma casa, um irmão agressivo, uma cidade onde cada esquina reafirmava seu estado deplorável, e que nada disso distribuiria o peso dos nossos problemas privados, que nada disso nos faria mais felizes, que nada disso ia adiar o fim daquela viagem, a separação iminente querendo ou não, eu tinha vontade de desaparecer (Bensimon, 2013, p. 159).

Importante estabelecer aqui uma cara reflexão: o amor, tema dos dois livros, transforma e contorna a existência das quatro mulheres, pautando e delimitando suas escolhas, assim como alimentando seus medos e suas carências. Há, é evidente, uma crítica indireta ao sistema social e familiar (nos dois livros a figura do pai se faz altiva e arrebatadora para as protagonistas), mas não é este sistema que valida ou proíbe a relação dos casais. Duas iguais e Todos nós adorávamos caubóis definem quem são os amantes nessas histórias de amor, mas não delimitam: Ana poderia amar Clara, que poderia amar Pedro, que poderia Amar João, que poderia amar Cora, que poderia amar Julia. Nessa não drummondiana quadrilha dos gêneros, os gêneros - singulares nas escolhas das autoras, plurais nas representações das personas - não importam. As personagens 
comportam qualquer um que leia a obra, porque não é uma obra com homossexuais ou sobre homossexuais ou para homossexuais. Diferentemente das obras que analisamos no levantamento de Luiz Mott, quando o trato do amor no terreno da homossexualidade feminina se fazia muito mais por sua função exótica, invulgar ou estranha. E diferente ainda das obras quase contemporâneas das autoras em análise, que buscavam muito mais o aspecto transgressor da temática, o que se tem delineado nos dois livros é uma história de amor comum, sobre pessoas comuns que são, por acaso, mulheres e, por acaso, homossexuais.

Os conceitos advindos da teoria queer, quando aplicados no campo da literatura, permitem uma visão emancipatória da diferença sexual ou das configurações identitárias sexuais que são convencionalmente entendidas como desviantes da norma. Cíntia Moscovich e Carol Bensimon são autoras que têm um olhar queer porque criam subjetividades que resistem à categorização, porque suas personagens não são nem uma coisa nem outra dentro dos rótulos socialmente estabelecidos. Ser homossexual é uma espécie de performance e, ao introduzir um erro nessa repetição dos gestos que tradicionalmente permitem identificá-las como homossexuais, elas constroem uma subjetividade que não é o que a convenção espera, mas também e algo de indefinido, é uma subjetividade que está em formação e para a qual ainda não há rótulos, questionando os regimes heteronormativos. Duas iguais e Todos nós adorávamos caubóis - tomando de empréstimo a fala de Anselmo Alós, ao abordar a teoria queer a respeito de outros livros - são

romances que subvertem a heteronormatividade em seus enredos, no sentido de se buscar as estratégias e o temas comuns com vistas a identificar as formas da resistência aos regimes heteronormativos da normalidade [...] Trata-se uma escrita que, ao mesmo tempo que nomeia, cria a identidade nomeada. Logo, as pesquisas em torno dos romances que problematizam as identidades sexuais são importantes e representativas na medida em que ficcionalizam uma realidade social ao mesmo tempo que a constroem (Alós, 2010, p. 842-859).

Nota-se em obras como as duas aqui analisadas que a desestabilização e desconstrução do imaginário (hetero)sexual feminino através da literatura subverte e reorganiza o imaginário social, intervindo nas esferas culturais e políticas, ao narrativizar essas 
personas construindo novos sentidos e colaborando para, ainda que timidamente, derrubar as fronteiras da exclusão. O discurso literário torna-se, então, ainda mais relevante se considerado como transgressor do discurso social, citando Foucault (1992, p. 9): "sabe-se bem que não se tem o direito de dizer tudo, que não se pode falar de tudo em qualquer circunstância, que qualquer um, enfim, não pode falar de qualquer coisa". Ainda nesse mesmo texto, Foucault lembra que as grades mais cerradas estão voltadas para o discurso da sexualidade. A julgar o lento caminho até agora conquistado, é necessário ainda concordar com ele. Mas uma concordância contornada pelo curioso olhar que percebe o corajoso caminho percorrido por autoras como Cíntia Moscovich e Carol Bensimon, não porque tenham ido ao limite da transgressão para falar do "diferente", mas porque foram diferentes para falar dos iguais. É porque suas personagens podem representar qualquer outra pessoa, homem ou mulher, é porque suas histórias falam muito mais de um eu e um outro que se conhecem e se reconhecem que é possível perceber um novo passo dado pela literatura. Ambas realizaram um desnivelamento dos discursos que as antecipam, transformando-os e ressignificando-os. Citando novamente Foucault:

O discurso nada mais é do que a reverberação de uma verdade nascendo diante de seus próprios olhos; e, quando tudo pode, enfim, tomar a forma do discurso, quando tudo pode ser dito e o discurso pode ser dito a propósito de tudo, isso se dá porque todas as coisas, tendo manifestado e intercambiado seu sentido, podem voltar à interioridade silenciosa da consciência de si (Foucault, 1992, p. 49).

As experiências de amor das personagens Clara, Ana, Julia e Cora tendem, enquanto humanas que são, a difundir-se em outros livros e outros discursos de outras (e por que não outros) escritoras. Não porque são obras que abordam o amor diante de personagens homossexuais femininas, mas porque transformam em literatura outras formas do amor cujos sentidos, ora manifestos e intercambiados, possuem agora espaço e voz. E, ainda, podem pela partilha validar um novo discurso literário em que não haja distinção de gênero ou sexualidade, mas novos fluxos e trânsitos para pensar a personagem homossexual feminina na literatura brasileira contemporânea. 


\section{Referências}

ALÓS, Anselmo (2010). Narrativas da sexualidade: pressupostos para uma poética queer. Revista de Estudos Feministas, Florianópolis, v. 18, n. 3, p. 837-864, set./dez.

BENSIMON, Carol (2013). Todos nós adorávamos caubóis. São Paulo: Companhia das Letras.

DABHOIWALA, Faramerz (2013). As origens do sexo: uma história da primeira revolução sexual. São Paulo: Globo.

DALCASTAGNÈ, Regina (2012). Literatura brasileira contemporânea: um território contestado. Vinhedo: Horizonte.

FOUCAULT, Michel (1992). A ordem do discurso. São Paulo: Loyola.

MOTT, Luiz (1987). O lesbianismo no Brasil. Porto Alegre: Mercado Aberto.

MOSCOVICH, Cíntia (2004). Duas iguais. Rio de Janeiro: Record.

RESENDE, Beatriz (2008). Contemporâneos. Rio de Janeiro: Casa da Palavra.

RIOS, Cassandra (1983). Eu sou uma lésbica: vamos brincar de gatinho? Rio de Janeiro: Record.

TREVISAN, João Silvério (1986/2007). Devassos no paraíso: a homossexualidade no Brasil, da colônia à atualidade. Rio de Janeiro: Record.

Recebido em outubro de 2015.

Aprovado em março de 2016.

\section{resumo/abstract/resumen}

\section{Cíntia Moscovich e Carol Bensimon: a personagem homossexual feminina na literatura brasileira contemporânea}

Juliana Gervason Defilippo

Este artigo pretende apresentar uma análise das personagens homossexuais femininas nas obras Duas iguais, de Cíntia Moscovich, e Todos nós adorávamos caubóis, de Carol Bensimon. Para tanto, apresenta um breve levantamento das abordagens presentes na literatura brasileira, do Barroco ao Modernismo, a partir do viés do amor entre mulheres. Ao realizar a comparação das duas obras contemporâneas com as obras antigas, busca-se compreender como se dá a representação da 
personagem homossexual feminina e o quanto essa representação foi se modificando ao longo dos anos no Brasil.

Palavras-chave: personagem homossexual, lesbianismo, Cíntia Moscovich, Carol Bensimon.

\section{Cíntia Moscovich and Carol Bensimon: female homosexual characters in contemporary Brazilian literature}

Juliana Gervason Defilippo

This article aims to present an analysis of female homosexual characters in the works Duas iguais, by Cintia Moscovich, and Todos nós adorávamos caubóis, by Carol Bensimon. It presents a brief survey of how Brazilian literature, from Baroque to Modernism, has represented the conception of love among women. The comparison of the two contemporary works with the older texts, attempts to understand how the representation of female homosexual characters is construed nowadays and how this representation was changed over the years in Brazil.

Keywords: homosexual characters, lesbianism, Cíntia Moscovich, Carol Bensimon.

\section{Cíntia Moscovich e Carol Bensimon: el personaje homosexual femenino en la literatura brasileña contemporánea}

Juliana Gervason Defilippo

Este artículo intenta presentar un análisis de los personajes homosexuales femeninos en las obras Duas iguais, de Cíntia Moscovich, y Todos nós adorávamos caubóis, de Carol Bensimon. Para ésto presenta una breve investigación de los enfoques presentes en la literatura brasileña, desde el Barroco hasta el Modernismo, a partir del carácter del amor entre mujeres. Al hacer la comparación entre las dos obras contemporáneas y las obras antiguas, se pretende comprender cómo se da la representación del personaje homosexual femenino y la manera en que esa representación fue modificándose a lo largo de los años en Brasil.

Palabras clave: personaje homosexual, lesbianismo, Cíntia Moscovich, Carol Bensimon. 